\title{
Bioethanol Dehydration Process using NaOH-Activated Zeolite at Various Concentration and Zeolite Weight
}

\author{
David Saidi, Akyunul Jannah, Anik Maunatin \\ ${ }^{1}$ Jurusan Kimia, Fakultas Sains dan Teknologi, Universitas Islam Negeri Maulana Malik Ibrahim Malang \\ Email: akyunul_jannah2008@yahoo.com
}

\begin{abstract}
Utilization of molasses as basic material for producing bioethanol becomes one of the promising efforts to fulfill the demand of fuel and diminish the dependence upon fossil fuel that its availability is increasingly rare. However, ethanol produced from fermentation of molasses has low purity. The purity could be increased by using dehydration method and zeolite activated by $\mathrm{NaOH}$ and alum as alumina source. The research is aimed to know the dehydration process of bioethanol use $\mathrm{NaOH}$-activated zeolite at various concentration and zeolite weight on the purification of bioethanol. In this research, the experiments could be categorized into 4 groups, they are activation of zeolite, fermentation, distillation, and dehydration process. Activation of natural zeolite performed by entering of sized 120-150 mesh zeolite powder was added to glass beaker that contains $\mathrm{NaOH}$ aqueous solution and followed by adding alum which took place at $80{ }^{\circ} \mathrm{C}$ for 8 hours and the final product calcinated at $600^{\circ} \mathrm{C}$ for 2 hour. Fermentation process was managed for 6 days and $\mathrm{pH}$ 5. Furthermore, bioethanol was separated by distillation method at $78,5-85{ }^{\circ} \mathrm{C}$ and followed by molecular sieve dehydration using zeolite activated by $\mathrm{NaOH}$ solution in variation of zeolite weight $(30,40$ and $50 \%)$ and $\mathrm{NaOH}$ concentration (1,2, 3 dan $4 \mathrm{M})$. The amount of bioethanol was measured by gas chromatography method. Bioethanol concentration as fermentation product is $29,8 \%$. The result revealed that dehydration with $30 \%$ w.t zeolite activated by $2 \mathrm{M} \mathrm{NaOH}$ solution had the best activity in bioethanol purification with amount of bioethanol is $53,76 \%$, Increased Levels of Bioethanol (ILB) value is $80,39 \%$ and Adsorption Capacity of Zeolite (ACZ) is $399,31 \%$.
\end{abstract}

Keywords: bioethanol, concentration of $\mathrm{NaOH}$, dehydration, molasses, molecular sieve, weight of zeolite.

\begin{abstract}
Abstrak
Pemanfaatan molase yang merupakan bahan dasar pembuatan bioetanol menjadi salah satu upaya untuk memenuhi kebutuhan bahan bakar serta mengurangi ketergantungan terhadap bahan bakar fosil yang keberadaanya semakin langka. Fermentasi molase akan menghasilkan etanol dengan kemurnian rendah sehingga perlu ditingkatkan kemurniannya menggunakan metode dehidrasi dengan zeolit yang diaktivasi menggunakan $\mathrm{NaOH}$ dan pemberian sumber alumina berupa tawas. Tujuan dari penelitian ini adalah mengetahui proses dehidrasi bioetanol menggunakan zeolit teraktivasi $\mathrm{NaOH}$ dengan variasi konsentrasi dan berat zeolit yang digunakan untuk memurnikan bioetanol. Metode penelitian ini meliputi proses aktivasi zeolit, fermentasi, destilasi dan dehidrasi. Aktivasi zeolit alam dilakukan dengan memasukkan zeolit ukuran 120-150 mesh ke dalam beaker glass yang telah berisi $\mathrm{NaOH}$ serta pemberian tawas yang berlangsung pada suhu $80{ }^{\circ} \mathrm{C}$ selama 8 jam dan kalsinasi pada suhu $600{ }^{\circ} \mathrm{C}$ selama 2 jam. Proses fermentasi dilakukan dengan lama fermentasi 6 hari serta $\mathrm{pH}$ 5. Selanjutnya bioetanol dipisahkan dengan metode destilasi pada suhu 78,5 - $85{ }^{\circ} \mathrm{C}$ dan dilanjutkan dengan dehidrasi molecular sieve menggunakan zeolit teaktivasi $\mathrm{NaOH}$ dengan variasi konsentrasi $\mathrm{NaOH}$ 1,2,3 dan $4 \mathrm{M}$, sedangkan variasi berat zeolit 30, 40 dan $50 \%$. Kadar bioetanol diukur menggunakan metode kromatografi gas. Kadar bioetanol hasil fermentasi adalah $29,8 \%$. Aplikasi zeolit hasil aktivasi pada proses dehidrasi bioetanol menunjukkan bahwa perlakuan A2B1 (konsentrasi NaOH $2 \mathrm{M}$ dan berat $30 \%$ ) merupakan perlakuan terbaik dalam aktivitas pemurnian bioetanol dengan kadar sebesar 53,76 \% dan nilai Peningkatan Kadar Bioetanol (PKB) 80,39 \% serta Kapasitas Adsorpsi Zeolit (KAZ) 399,31 \%.
\end{abstract}

Kata kunci: Bioetanol, konsentrasi $\mathrm{NaOH}$, dehidrasi, molase, molecular sieve, berat zeolit

\section{PENDAHULUAN}

Penggunaan bahan bakar minyak yang berasal dari fosil sudah diketahui dapat menimbulkan polusi rumah kaca terutama $\mathrm{CO}_{2} \quad$ sehingga dapat 
menyebabakan pemanasan global. Gas pembuangan tersebut juga dapat menyebabkan gangguan pernapasan, kanker bahkan kemandulan (Magdalena, 2007). Oleh karena itu sudah saatnya dilakukan pengembangan sumber energi alternatif yang diharapkan dapat memenuhi permintaan kebutuhan bahan bakar. Salah satunya adalah memanfaatkan limbah industry pertanian molase (tetes tebu)

Molase merupakan hasil samping dari industri pengolahan gula yang masih mengandung gula cukup tinggi. Kandungan gula dalam molase merupakan kebutuhan utama dalam proses fermentasi, karena gula tersebut akan dikonversi menjadi bioetanol. Kandungan molase diantaranya glukosa $21,7 \%$, sukrosa $34,19 \%$, air $26,46 \%$, dan abu $17,26 \%$ sehingga merupakan bahan baku potensial untuk pembuatan etanol (Tarigan, 2009).

Bioetanol yang dihasilkan dari proses fermentasi mempunyai kemurnian yang cukup rendah, karena produk samping proses glikolisis juga menghasilkan asamasam organic lainnya. Oleh karena itu perlu dilakukan metode pemurnian destilasi dan dehidrasi guna mendapatkan etanol dengan kemurnian tinggi.

Salah satu metode dehidrasi yang bisa digunakan adalah menggunakan zeolit yang berfungsi sebagai materi molecular sieve yang dikontakkan dengan etanol (prinsip adsorpsi) hasil destilasi.

Zeolit alam merupakan mineral yang tersusun dari kerangka silika-alumina tetrahedal secara tiga dimensi, mempunyai rongga dan saluran yang saling berhungan Sehingga menyebabkan bagian dari permukaannya menjadi luas (Setiadi dan Pertiwi, 2005). Akan tetapi penggunaan zeolit alam dalam bidang dehidrasi adsorbsi masih terbatas karena distribusi pori yang tidak seragam, sehingga perlu dilakukan aktivasi
Proses aktivasi diperlukan untuk meningkatkan sifat khusus zeolit dan menghilangkan unsur pengotor (Rosita dkk, 2004). Secara umum ada tiga proses aktivasi yang bisa dilakukan terhadap zeolit alam, yaitu aktivasi secara fisika dengan pemanasan, aktivasi secara kimia dengan asam dan aktivasi secara kimia dengan basa. Proses aktivasi dengan panas dapat dilakukan pada suhu antara $200-400{ }^{\circ} \mathrm{C}$ selama beberapa jam. Proses ini bertujuan untuk menghilangkan kandungan air yang masih terkandung di dalamnya. Sedangkan pada proses aktivasi secara kimia dapat dilakukan dengan cara aktivasi asam dan aktivasi basa.

Aktivasi zeolit dengan basa akan menjadi lebih polar bila dibandingkan dengan zeolit yang diaktivasi dengan asam (Jozefaciuk dan Bowanko, 2002). Aktivasi zeolit dengan basa juga dilakukan untuk memperkecil rasio $\mathrm{Si} / \mathrm{Al}$ yang menjadi faktor utama penyebab sifat hidrofilik meningkat sesuai dengan zeolit 3A. Affandi (2011) melaporkan bahwa kemampuan adsorpsi air dalam zeolit teraktivasi $\mathrm{HCl}$ hanya sebesar 0,69\% sedangkan pada aktivasi $\mathrm{NaOH}$ sebesar 5,03\%.

Dalam penelitian ini dilakukan aktivasi zeolit dengan $\mathrm{NaOH}$ dan penambahan tawas sebagai sumber alumina untuk memperkecil rasio $\mathrm{Si} / \mathrm{Al}$ zeolit.

\section{METODE PENELITIAN Alat Penelitian}

Alat yang digunakan dalam penelitian ini antara lain ayakan 120 dan 150 mesh, neraca analitik, bluetip, aluminium foil, botol semprot, furnice, thermometer, laminar air flow, gelas beaker, Erlenmeyer, tabung reaksi, labu ukur, pipet ukur, pipet volume, bola hisap, pipet tetes, kaca arloji, pengaduk gelas, spatula, corong kaca, kertas saring, oven, hotplate, autoclave, furnice, shaker, neraca analitik, mortar dan alu, desikator, seperangkat alat destilasi dan 1 set GC. 


\section{Bahan Penelitian}

Bahan-bahan yang diperlukan dalam penelitian ini adalah molase, aquades, zeolit dari daerah Sumber Manjing Malang, padatan $\mathrm{NaOH}$ p.a, larutan $\mathrm{H}_{2} \mathrm{SO}_{4}$, urea, glukosa, yeast extract, pepton, padatan tawas, indikator universal.

\section{PROSEDUR PENELITIAN Preparasi}

Serbuk zeolit alam Sumbermanjing kabupaten Malang diayak dengan ukuran lolos 120-150 mesh dan dicuci dengan akuades. Disaring dengan kertas saring dan residu dikeringkan dalam oven pada suhu $120{ }^{\circ} \mathrm{C}$ selama 4 jam (Mutngimaturrahmah, dkk., 2010).

Aktivasi Zeolit

Zeolit alam hasil preparasi ditimbang sebanyak 25 gram dan dimasukkan ke dalam beaker glass berisi $450 \mathrm{~mL} \mathrm{NaOH}$ masing-masing dengan konsentrasi $(1,2,3$ dan $4 \mathrm{M})$ dan padatan tawas 107,38 gram (Nais, 2011). Beaker glass dipanasakan pada suhu $80{ }^{\circ} \mathrm{C}$ selama 8 jam. Kemudian bahan disaring untuk memisahkan antara liquid dan padatan. Material padat yang diperoleh dicuci berulang dengan aquadest sampai $\mathrm{pH}$ netral (Zuhaidha, 2012). Kristal dikeringkan di oven pada suhu $80{ }^{\circ} \mathrm{C}$ selama 10 jam dan dikalsinasi pada suhu $650{ }^{\circ} \mathrm{C}$ selama 2 jam (Nais, 2011).

\section{Pembuatan Media}

a. Pembuatan Media YPGA (Yeast Extract Pepton Glucose Agar) (Hartina, 2013)

Media YPGA dibuat dengan menimbang $0,5 \mathrm{~g}$ pepton, $0,25 \mathrm{~g}$ yeast extract, $1 \mathrm{~g}$ glukosa, dan 1,5 g agar, bahanbahan tersebut kemudian dilarutkan dengan akuades $50 \mathrm{~mL}$ dan dipanaskan hingga mendidih. Selanjutnya media YPGA disterilisasi dengan autoclave pada suhu
$121{ }^{\circ} \mathrm{C}$ dan tekanan 15 psi selama 15 menit. Larutan tersebut kemudian didinginkan dalam tabung reaksi pada keadaan miring hingga memadat. Media YPGA ini digunakan untuk regenerasi Saccharomyces cerevisiae.

\section{b. Pembuatan Media YPGB (Yeast Extract Pepton Glucose Broth ) (Hartina, 2013)}

Media YPGB dibuat dengan menimbang 2,5 $\mathrm{g}$ pepton, 1,25 $\mathrm{g}$ yeast extract, dan $5 \mathrm{~g}$ glukosa, kemudian bahanbahan tersebut dilarutkan dengan akuades $250 \mathrm{~mL}$ dan dipanaskan hingga mendidih. Selanjutnya media YPGB disterilisasi dengan autoclave pada suhu $121{ }^{\circ} \mathrm{C}$ dan tekanan 15 psi selama 15 menit. Media YPGB ini digunakan untuk pembuatan inokulum.

\section{Regenerasi Saccharomyces cereviciae}

Biakan Saccharomyces cereviciae diambil sebanyak dua ose dan dimasukkan ke dalam media YPGA, kemudian diinkubasi selama 2 hari pada suhu ruang. Saccharomyces cereviciae yang telah diregenerasi digunakan untuk pembuatan inokulum.

\section{Pembuatan Inokulum (Hartina, 2013)}

Pembuatan inokulum ini dilakukan dengan cara memindakan 2 ose Saccharomyces cereviciae ke dalam 100 $\mathrm{mL}$ media YPGB, kemudian di goyang dengan shaker pada kecepatan $150 \mathrm{rpm}$ selama 32 jam pada suhu $30{ }^{\circ} \mathrm{C}$. Inokulum digunakan untuk fermentasi molase.

\section{Preparasi Bahan Baku}

Pembuatan Sampel Molase (Kultsum, 2009)

Molase yang telah diencerkan hingga $20 \%$ Brix diambil sebanyak $600 \mathrm{~mL}$ kemudian dipanaskan dengan suhu $70{ }^{\circ} \mathrm{C}$ selama 30 menit dan disaring dengan kertas saring. Filtrat yang diperoleh ditambahkan urea sebanyak $0,6 \%$, kemudian filtrat 
dibagi menjadi 3 masing-masing $200 \mathrm{~mL}$. Ditambahkan larutan $\mathrm{H}_{2} \mathrm{SO}_{4} \quad 0,1 \mathrm{~N}$ untuk mengatur $\mathrm{pH}$ yang dikehendaki yaitu $\mathrm{pH} 5$. Selanjutnya sampel disterilisasi ke dalam autoclave pada suhu $121{ }^{\circ} \mathrm{C}$ dan tekanan 15 psi selama 2 jam. Selanjutnya digunakan untuk fermentasi pembuatan bioetanol.

\section{Fermentasi Molase Untuk Menghasilkan Etanol}

Molase yang telah dipreparasi dengan pH 5 pada volume $200 \mathrm{~mL}$ ditambahkan inokulum Saccharomyces cereviciae yang telah mencapai fase log sebanyak $20 \mathrm{~mL}$ kemudian Erlenmeyer ditutup dengan kapas dan dishaker dengan kecepatan $150 \mathrm{rpm}$ selama waktu fermentasi yang dikehendaki yaitu 3 hari (Hartina, 2013). Setelah proses fermentasi selesai, dilakukan penyaringan untuk memisahkan kotoran yang ada dan untuk memisahkan bioetanol dari media fermentasi selanjutnya dilakukan proses destilasi.

\section{Destilasi Hasil Fermentasi Molase}

Dirancang alat destilasi.

Dimasukkan filtrat hasil fermentasi ke labu alas bulat yang telah di isi dengan batu didih sehingga volumenya setengah volume labu. Dialirkan air kondensor menggunakan air es lalu dihidupkan mantel pemanas dengan suhu sedang. Ditampung destilat pada suhu $78,5-85^{\circ} \mathrm{C}$. Destilasi dihentikan jika sudah tidak ada destilat yang menetes dalam Erlenmeyer. Destilat yang didapat lalu dimasukkan dalam botol dan ditutup rapat. Destilat yang disimpan dalam botol siap untuk dianalisis dengan GC.

\section{Dehidrasi Etanol Hasil Destilasi Menggunakan Zeolit Teraktivasi $\mathrm{NaOH}$}

Dehidrasi menggunakan metode adsorbsi dilakukan menggunakan zeolit yang dihasilkan pada proses aktivasi $\mathrm{NaOH}$ (perlakuan 3.5.1.1). Perbandingan massa zeolit terhadap etanol yang digunakan pada proses dehidrasi adalah $30 \%, 40 \%$ dan 50 $\%$ ke dalam volume etanol hasil destilasi.
Percobaan ini diawali dengan memasukkan etanol $20 \mathrm{~mL}$ hasil destilasi ke dalam Erlenmeyer lalu ditambahkan zeolit (Novitasari, 2012). Diaduk perlahan selama 30 menit pada suhu ruang menggunakan magnetic stirrer (Erlenmeyer ditutup), adsorben zeolit dipisahkan dengan pengendapan dan filtrasi (Nais, 2011). Kemudian dihitung perubahan konsentrasi etanol.

\section{Analisis Kadar Bioetanol dengan Kromatografi Gas (KG)}

Proses analisis kadar etanol dengan $\mathrm{KG}$ yaitu sebagai berikut; masing-masing destilat hasil destilasi diambil $1 \mu \mathrm{L}$ dan diinjeksikan ke dalam alat melalui tempat injeksi. Luas puncak etanol dari kromatogram dihitung dengan membandingkan luas area sampel dengan luas area standar internal asetonitril.

\section{HASIL DAN PEMBAHASAN Preparasi Sampel}

Zeolit yang digunakan dalam penelitian ini adalah zeolit alam yang berasal dari Sumbermanjing Malang. Dari analisis XRD yang dilakukan oleh Botianovi (2012) didapatkan hasil bahwa zeolit alam Malang termasuk golongan mordenit. Zeolit alam kemudian diayak dengan menggunakan ukuran lolos 120-150 mesh agar diperoleh homogenitas luas permukaan zeolit sehingga kemampuan adsorpsinya dapat lebih optimal.

Aktivasi Zeolit

Aktivasi zeolit secara kimia bertujuan untuk mengurangi kandungan logam, membersihkan permukaan pori dan mengatur kembali letak atom yang dipertukarkan (Syafii, dkk., 2010). Proses aktivasi menggunakan pelarut basa yaitu $\mathrm{NaOH}$. Pemilihan pelarut didasarkan pada kemampuannya dalam melarutkan unsurunsur tertentu sehingga mengurangi rasio $\mathrm{Si} / \mathrm{Al}$. Rasio $\mathrm{Si} / \mathrm{Al}$ adalah perbandingan komposisi persenyawaan $\mathrm{SiO}_{2}$ dan $\mathrm{Al}_{2} \mathrm{O}_{3}$ yang menjadikan zeolit lebih bersifat 
hidrofobik (tidak suka air) atau hidrofilik (suka air) (Jozefaciuk dan Bowanko, 2002). Penurunan rasio $\mathrm{Si} / \mathrm{Al}$ terjadi karena $\mathrm{NaOH}$ akan melarutkan tawas dan mengendapkan unsur kation $\mathrm{Al}^{3+}$ dalam bentuk $\mathrm{Al}(\mathrm{OH})_{3}$. Selain penurunan rasio $\mathrm{Si} / \mathrm{Al}$, aktivasi dengan $\mathrm{NaOH}$ juga bertujuan untuk menghilangkan ion-ion tertentu dari kerangka zeolit dan menggantinya dengan ion $\mathrm{Na}^{+}$sehingga zeolit alam mempunyai kondisi yang semakin mendekati bentuk homoionik.

Berikut adalah ilustrasi proses aktivasi zeolit alam dengan larutan $\mathrm{NaOH}$.

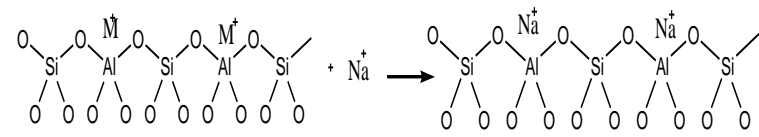

Gambar 1. Dugaan pertukaran ion pada proses aktivasi dengan basa (Inglezakis dkk., 2001)

\section{Zeolit hasil perendaman $\mathrm{NaOH}$} dicuci dengan akuades hingga filtrat menunjukkan $\mathrm{pH}$ netral. Kemudian doven pada suhu $80{ }^{\circ} \mathrm{C}$ selama 10 jam untuk menghilangkan molekul air dan selanjutnya dikalsinasi. Berikut adalah perbandingan zeolit sebelum dan sesudah aktivasi.

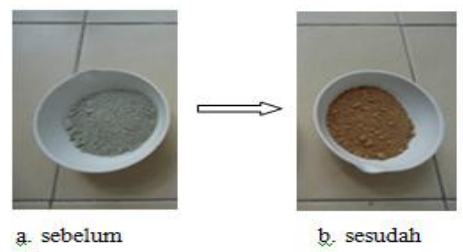

Gambar 2. Perbandingan zeolit sebelum dan sesudah aktivasi

\section{Fermentasi Molase}

Proses fermentasi diawali dengan pembuatan media YPGA sebagai media padat untuk regenerasi Saccharomyces cerevisiae. sedangkan media YPGB (Yeast Extract Pepton Glucose Broth) digunakan untuk pembuatan inokulum. Media-media ini disterilisasi. Selanjutnya molase yang diperoleh dipreparasi dengan mengkondisikan kadar gula serta $\mathrm{pH}$. Molase yang telah dipreparasi ditambahkan inokulum Saccharomyces cereviciae.

Secara singkat perubahan biokimia selama fermentasi molase dapat ditulis sebagai berikut: Saccharomyces cerevisiae memanfaatkan disakarida seperti sukrosa sebagai sumber makanan karena Saccharomyces cerevisiae dapat menghasilkan dua enzim, yaitu enzim invertase dan enzim zimase. Enzim invertase berfungsi memecah sukrosa menjadi monosakarida (glukosa dan fruktosa) (Prabawa dkk., 2012). Selanjutnya glukosa dan fruktosa tersebut diubah menjadi bioetanol oleh enzim zimase (Hasanah, 2008).

Setelah proses fermentasi selesai, dilakukan penyaringan untuk memisahkan kotoran yang ada dan untuk memisahkan bioetanol dari media fermentasi.

\section{Destilasi Molase Hasil Fermentasi}

Langkah-langkah pemisahan fase cair hasil fermentasi dengan destilasi yaitu, dimasukkan filtrat hasil fermentasi ke labu alas bulat yang telah di isi dengan batu didih sehingga volumenya setengah volume labu. Dialirkan air kondensor menggunakan air es lalu dihidupkan mantel pemanas dengan suhu sedang. Ditampung destilat pada suhu 78,5 - $85{ }^{\circ} \mathrm{C}$. Senyawa yang menguap terlebih dahulu adalah etanol karena titik didih rendah yaitu $78,9{ }^{\circ} \mathrm{C}$ dibandingkan dengan senyawa-senyawa lain seperti glukosa dengan titik didih 146 ${ }^{\circ} \mathrm{C}$ dan asam asetat dengan titik didih 118,1 ${ }^{\circ} \mathrm{C}$ atau air $100{ }^{\circ} \mathrm{C}$. Semua fasa cair yang ada dalam sampel yang keluar dari labu alas bulat akan keluar melalui pipa outnet dan diembunkan kembali dengan pendingin atau kondensor, destilat yang sudah diembunkan akan ditampung dalam wadah terpisah. Destilasi dihentikan jika sudah 
tidak ada destilat yang menetes dalam Erlenmeyer. Destilat yang didapat lalu dimasukkan dalam botol dan ditutup rapat agar tidak mengalami penguapan karena etanol mempunyai sifat mudah menguap. Destilat yang disimpan dalam botol siap untuk dianalisis dengan GC. Hasil GC menunjukkan bahwa kadar etanol hasil destilasi adalah $29,80 \%$.

\section{Dehidrasi Etanol Hasil Destilasi Menggunakan Zeolit Teraktivasi $\mathrm{NaOH}$}

Dehidrasi etanol menggunakan metode adsorbsi dilakukan menggunakan zeolit yang dihasilkan pada proses aktivasi $\mathrm{NaOH}$. Proses aktivasi zeolit menggunakan $\mathrm{NaOH}$ dianggap mampu menurunkan rasio $\mathrm{Si} / \mathrm{Al}$ zeolit yang berperan penting dalam proses adsorpsi air. Zeolit dengan rasio Si/Al paling kecil akan mampu mengikat air lebih banyak karena ukuran pori zeolit lebih spesifik yakni 3 A sehingga etanol tidak masuk ke dalam pori (ukuran partikel zeolit 4,4 A) (Khaidir, 2012).

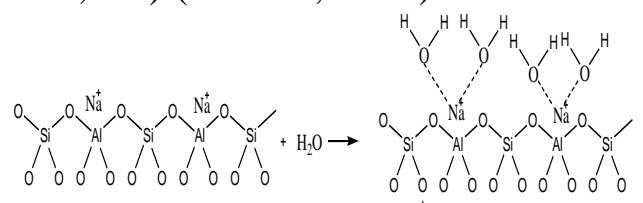

Gambar 3. Interaksi ion $\mathrm{Na}^{+}$dengan molekul air (Jozefaciuk dan Bowanko, 2002)

Tabel 1. Hasil GC proses dehidrasi etanol

\begin{tabular}{|c|c|c|}
\hline Sampel & $\begin{array}{c}\text { Kadar Bietanol } \\
\text { Hasil Destilasi } \\
(\% \mathrm{v} / \mathrm{v})\end{array}$ & $\begin{array}{c}\text { Kadar Bietanol } \\
\text { Hasil Dehidrasi } \\
(\% \mathrm{v} / \mathrm{v})\end{array}$ \\
\hline $\mathrm{A}_{1} \mathrm{~B}_{1}$ & \multirow{12}{*}{29,8} & 11,97 \\
\hline $\mathrm{A}_{1} \mathrm{~B}_{2}$ & & 10,71 \\
\hline $\mathrm{A}_{1} \mathrm{~B}_{3}$ & & 13,49 \\
\hline $\mathrm{A}_{2} \mathrm{~B}_{1}$ & & 53,76 \\
\hline $\mathrm{A}_{2} \mathrm{~B}_{2}$ & & 10,72 \\
\hline $\mathrm{A}_{2} \mathrm{~B}_{3}$ & & 11,14 \\
\hline $\mathrm{A}_{3} \mathrm{~B}_{1}$ & & 8,68 \\
\hline $\mathrm{A}_{3} \mathrm{~B}_{2}$ & & 10,79 \\
\hline $\mathrm{A}_{3} \mathrm{~B}_{3}$ & & 8,47 \\
\hline $\mathrm{A}_{4} \mathrm{~B}_{1}$ & & 10,30 \\
\hline $\mathrm{A}_{4} \mathrm{~B}_{2}$ & & 7,67 \\
\hline $\mathrm{A}_{4} \mathrm{~B}_{3}$ & & 10,73 \\
\hline
\end{tabular}

Selain rasio $\mathrm{Si} / \mathrm{Al}$, proses adsorpsi juga dipengaruhi oleh ion-ion logam yang melingkupi permukaan zeolit, sebagai contoh ion $\mathrm{Na}^{+}$. Zeolit dengan kandungan logam natrium lebih tinggi akan lebih mudah mengikat air dibandingkan yang lainnya. Jadi, molekul-molekul air tidak hanya terperangkap dalam pori-pori zeolit, tetapi berinteraksi juga dengan ion natrium yang mengelilingi permukaan zeolit. Molekul air terkumpul pada kation $\mathrm{Na}^{+}$ seperti pada gambar 3 .

Adapun hasil GC dari proses dehidrasi disajikan pada tabel 1 .

\section{KESIMPULAN}

Berdasarkan penelitian dapat disimpulkan bahwa kadar bioetanol hasil dehidrasi menggunakan zeolit teraktivasi $\mathrm{NaOH}$ dengan variasi konsentrasi $(1,2,3$ dan 4M) dan berat zeolit (30,40 dan $50 \%)$ terendah diperoleh pada perlakuan $\mathrm{A}_{4} \mathrm{~B}_{2}$ (konsentrasi 2 dan berat $40 \%$ ) sebesar 7,67 $\% \quad(\mathrm{v} / \mathrm{v})$. Sedangkan bioetanol tertinggi diperoleh pada perlakuan $\mathrm{A}_{2} \mathrm{~B}_{1}$ (konsentrasi 2 dan berat $30 \%$ ) dengan kadar bioetanol sebesar 53,76\% (v/v).

\section{DAFTAR PUSTAKA}

Affandi, F., Hadisi, H. 2011. Pengaruh Metode Aktivasi Zeolit Alam Sebagai Bahan Penurun Temperatur Campuran Beraspal Hangat. Bandung: Pusat Litbang Jalan dan Jembatan

Botianovi, A. 2012. Modifikasi Pori Zeolit Alam Malang dari Mikropori ke Mesopori dengan Penambahan Surfaktan CTABr (Cethyltrimethylamoniumbromide). Skripsi. Jurusan Kimia Fakultas Sains dan Teknologi Universitas Islam Negeri Maulana Malik Ibrahim Malang.

Hartina, F. 2013. Fermentasi Tetes Tebu Dari Pupuk Pabrik Gula Pagotan Madiun Menggunakan 
Saccharomyces cereveiae Untuk Menghasilkan Bioetanol Dengan Variasi pH dan Lama Fermentasi. Skripsi. Jurusan Kimia Fakultas Sains dan Teknologi Universitas Islam Negeri Maulana Malik Ibrahim Malang.

Inglezakis, V.J., Papadeas, C.D., Loizidou, M.D., and Grigoropoulou, H.P., (2001), Effects of Pretreatment on Physical and Ion Exchange Properties of Natural Clinoptilolite, Environmental Technology, 22, pp. 75-82.

Jozefaciuk, G. and Bowanko, G. 2002. Effect of Acid and Alkali Treatments on Surface Areas and Adsorption Energies of Selected Minerals, Journal Clays and Clay Minerals, 50(6), pp. 771-783.

Khaidir. 2012. Dehidrasi Bioetanol Menggunakan Zeolit Alam Termodifikasi. Tesis Diterbitkan. Jawa Barat: IPB Press

Kultsum, U. 2009. Pengaruh Variasi Nira Tebu (Saccharum Officinarum) dari Beberapa Varietas Tebu Dengan Penambahan Sumber Nitrogen (N) dari Tepung Kedelai Hitam (Glycine Soja) sebagai Substrat Terhadap Efisiensi Fermentasi Etanol. Skripsi Diterbitkan. Malang: jurusan Kimia Fakultas Sains dan Teknologi Universitas Islam Negeri.

Mutngimaturrahmah, Gunawan, dan Khabibi. 2010. Aplikasi Zeolit Alam Termodifikasi HDTMA sebagai Adsorben Fenol. Skripsi Diterbitkan
Semarang : Jurusan Kimia UNDIP Semarang.

Nais, M.F., Wibawa, Gede. 2011. Peningkatan Kualitas Zeolit Alam Indoensia Sebagai Adsorben pada Produksi Bioethanol Fuel Grade. Skripsi Diterbitkan. Surabaya: ITS

Novitasari, D. 2012. Pemurnian Bioetanol Menggunakan Proses Adsorbsi Dan Destilasi Adsorbsi Dengan Adsorben Zeolit. Skripsi Diterbitkan. Semarang: Undip

Rosita, N., Erawati, T., dan Moegihardjo, M. 2004. Pengaruh Perbedaan Metode Aktivasi Terhadap Efektivitas Zeolit sebagai Adsorben. Majalah Farmasi Airlangga

Setiadi dan Pertiwi, A. 2005. Preparasi dan Karakterisasi Zeolit Alam untuk Konversi Senyawa Abe Menjadi Hidrokarbon. Prosiding Konggres dan Simposium Nasional Kedua MKICS ISSN: $0216-4183$.

Syafii, F., Sugiarti, S., dan Charlena. 2010. Modifikasi Zeolit Melalui Interaksi Dengan $\quad \mathrm{Fe}(\mathrm{OH})_{3} \quad$ Untuk Meningkatkan Kapasitas Tukar Anion. Departemen Kimia, FMIPA Institut Pertanian Bogor.

Tarigan. 2009. Pra Rancangan Pembuatan pabrik bioetanol dari Molase Kapasitas produksi 98.000 ton/tahun.

http:/Repository.usu.ac.id. Diakses tanggal 24 Maret 2013.

Zuhaidha, N. 2012. Zeolit Alam Teraktivasi Basa Untuk Pemurnian Bioetanol. Skripsi Diterbitkan Bogor: IPB 